\title{
Growth Rate of Wheat Crop in Varanasi division of Eastern Uttar Pradesh, India
}

\author{
Piyush Kumar Singh ${ }^{1 *}$, Neeraj Singh ${ }^{1}$, Sunil Kumar ${ }^{1}$ and V.D. Chaturvedi ${ }^{2}$
}

${ }^{1}$ Department of Agricultural Statistics, College of Agriculture, Narendra Dev University of Agriculture and Technology, Kumarganj-Faizabad (UP), 224-229, India

${ }^{2}$ Department of Genetics and Plant Breeding, College of Agriculture, Narendra Dev

University of Agriculture and Technology, Kumarganj-Faizabad (UP), 224-229, India

*Corresponding author

\section{A B S T R A C T}

\section{Keywords}

Wheat, Growth, Trend,

Tabular analysis, Linear

Growth Rate (LGR),

Compound Growth Rate (CGR)

Article Info

Accepted:

16 April 2018

Available Online:

10 May 2018
Wheat (Triticum aestivum L.) is most important staple crop of the world and is major constituents of Indian agriculture and nutritional security due to their high yield, economic viability, ability to generate on-farm and offfarm employment. The paper analyzes the growth in terms of area, production and productivity of wheat in Varanasi Division of Eastern Uttar Pradesh. The growth was examined by Linear Growth Rate (LGR) and Compound Annual Growth rate (CAGR) for period 2000-01 to 2014-15.

\section{Introduction}

Varanasi Division consists of 4 districts of Varanasi, Chandauli, Ghazipur, and Jaunpur.

Wheat (Triticum species) is a crop of global significance. It is grown in diversified environments.

It is a staple food of millions of people. Approximately one-sixth of the total arable land in the world is cultivated with wheat is grown in all the continents of the world. It supplies about 20 per cent of the food calories for the world's growing population. Global wheat production touched 729 million tonnes in 2013-14. India is the second largest producer of wheat after China.

\section{Materials and Methods}

The present study is primarily based on the time series secondary data- Area, Production and Productivity of Wheat in Varanasi division of eastern Uttar Pradesh.

Based on Sankhikiya Patrika, Agricultural Statistics at a Glance, etc. 


\section{Estimation of growth rate}

Linear growth rate (LGR) and compound growth rate (CGR) were used for the estimation of growth rates for area, production and productivity of Wheat in Varanasi division of eastern Uttar Pradesh, India.

\section{By linear function}

Linear function is given by the equation:

$X_{t}=a t+b$

Where,

$\mathrm{t}$ is the time in years, independent variable

$\mathrm{X}_{\mathrm{t}}$ is the trend value of the dependent variable (production/area/productivity)

$\mathrm{a}$ and $\mathrm{b}$ are constants

The above equation is fitted by using the least squares method of estimation.

The linear growth rate is calculated by the formula:

Linear growth rate $($ LGR $\%)=\frac{\frac{b}{y}}{\bar{y}} \times 100$

\section{By compound function}

Compound function is given by the equation:

$X_{t}=a b^{t}$

$\log X_{t}=\log a+t \log b$

Where,

$\mathrm{X}_{\mathrm{t}}$ is the characteristic (area or production or productivity)

$\mathrm{t}$ is the time in years, independent variable $\mathrm{a}$ and $\mathrm{b}$ are constants

The ' $a$ ' and ' $b$ ' are calculated by applying the method of Least Squares.

Compound growth rate worked out as:

Compound growth rate: CGR $(\%)=($ antilog $b$ - 1) x 100

\section{Results and Discussion}

The linear growth rates and compound growth rates for the study period of 2000-01 to 201415 are estimated by fitting the linear function and compound function to the area, production and productivity of Wheat.

Growth rates in production, area and productivity of wheat crops in Varanasi division of Eastern Uttar Pradesh

Above graph shows alarming year to year fluctuation in particular period 2013-15 moving average has less year to year fluctuation.

Above graphs shows increasing trend of area indicating importance of wheat crop in the area. Production in year 2013-14 \& 2014-15 declined the fact that increased area was under wheat during the period this indicates challenge in production which need to be addressed for sustainable growth

Above graphs shows marked decline of productivity in year 2013-2015 due to severe drought.

\section{Growth rates in production}

In Varanasi division the coefficient of variation is 16.93. Linear and compound growth rates were 2.47 and 2.48 per-cent per annum respectively. The production of wheat in Varanasi division of Eastern Uttar Pradesh exhibited a positive trend (Fig. 1). 
Fig.1 Trend of production of wheat in Varanasi division of Eastern Uttar Pradesh from 2000-01 to 2014-15

\section{Production (in Metric Tonnes)}

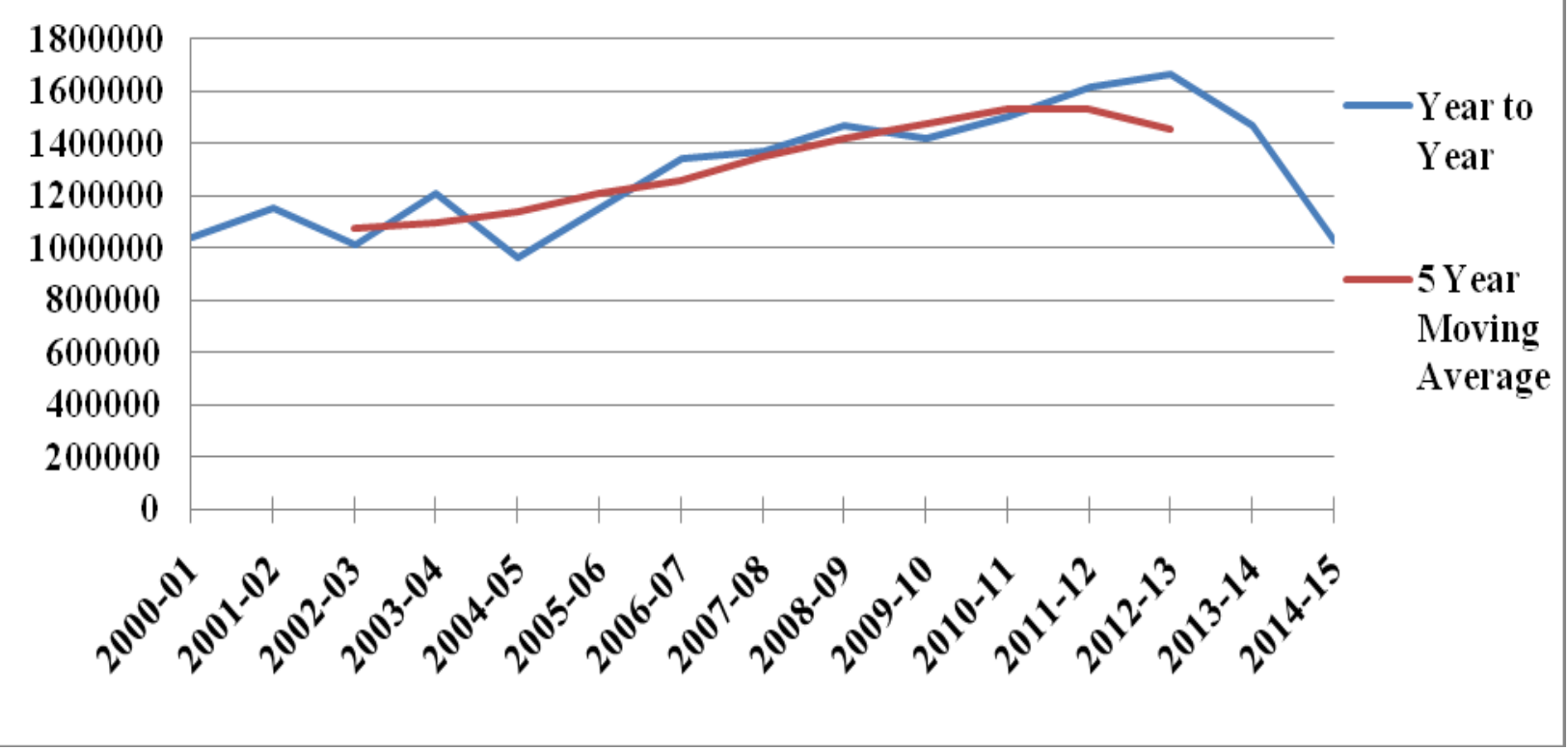

Fig.2 Trend of area under wheat in Varanasi division of Eastern Uttar Pradesh from 2000-01 to 2014-15

\section{Area Under Wheat (in Hect.)}

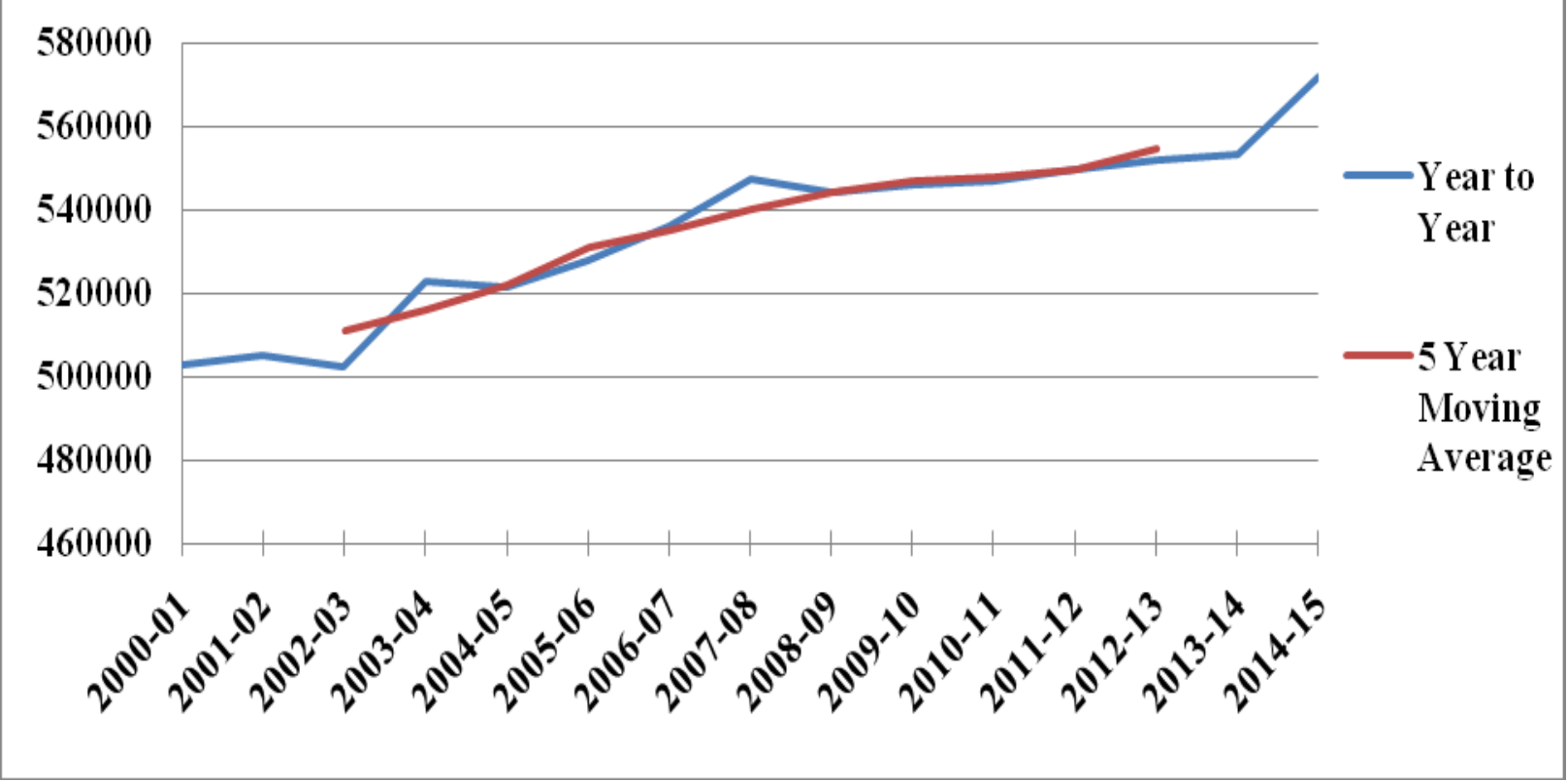


Fig.3 Trend of productivity of wheat in Varanasi Division of Eastern Uttar Pradesh from 200001 to $2014-15$

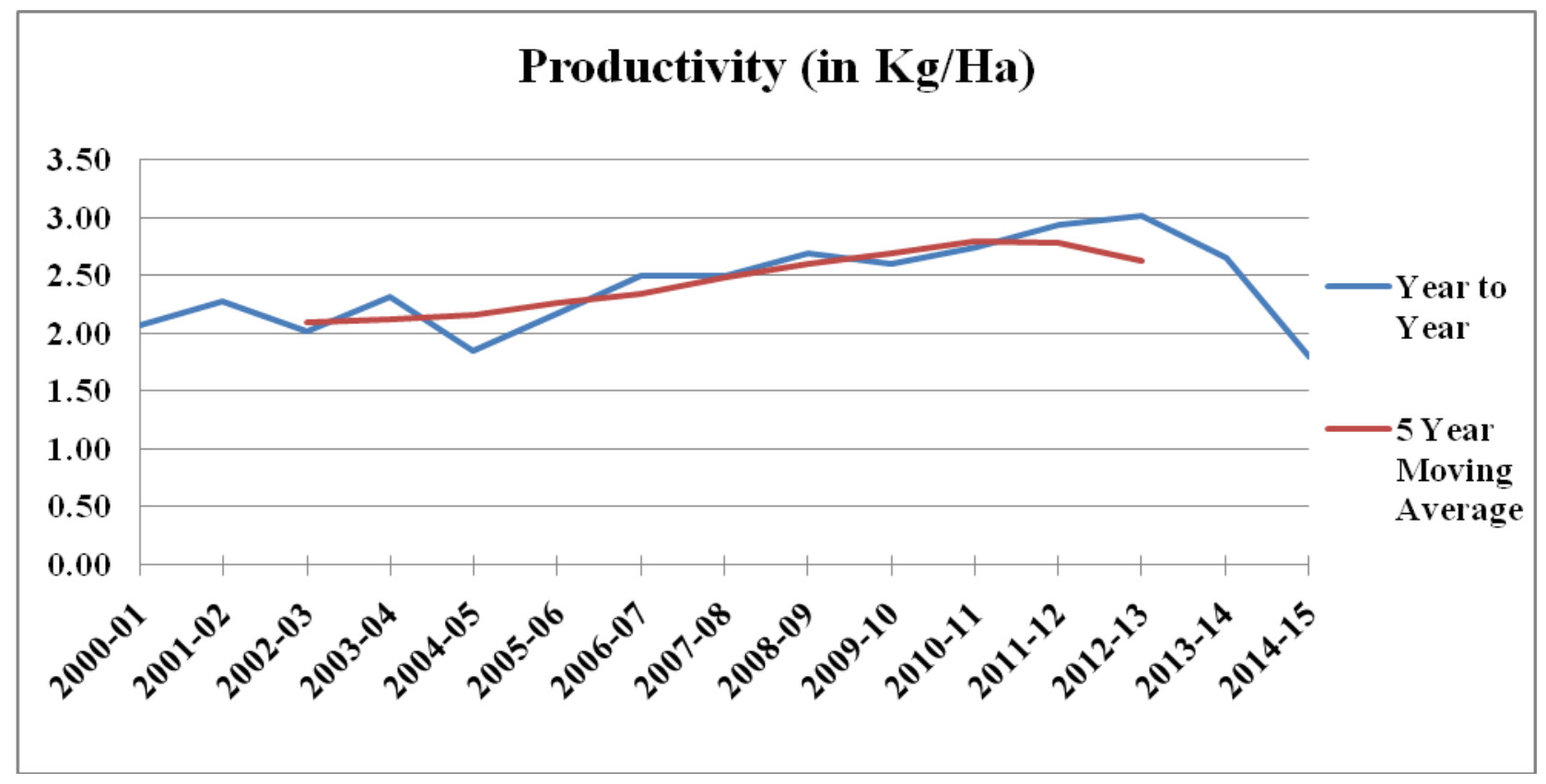

Table.1 LGR, CGR and C.V. of Varanasi Division in respect to production, area and productivity 2000-01 to 2014-15

\begin{tabular}{|c|c|c|c|}
\hline Year & $\begin{array}{c}\text { Production (in } \\
\text { metric Tonnes) }\end{array}$ & $\begin{array}{c}\text { Area (in } \\
\text { Ha.) }\end{array}$ & $\begin{array}{c}\text { Productivity } \\
\text { (in Kg/Ha) }\end{array}$ \\
\hline $\mathbf{2 0 0 0 - 0 1}$ & 1199336 & 502907 & 2064.34 \\
\hline $\mathbf{2 0 0 1 - 0 2}$ & 1151304 & 505274 & 2278.12 \\
\hline $\mathbf{2 0 0 2 - 0 3}$ & 1012173 & 502519 & 2014.67 \\
\hline $\mathbf{2 0 0 3 - 0 4}$ & 1208873 & 522930 & 2312.23 \\
\hline $\mathbf{2 0 0 4 - 0 5}$ & 960843 & 521391 & 1843.08 \\
\hline $\mathbf{2 0 0 5 - 0 6}$ & 1148264 & 527823 & 2176.56 \\
\hline $\mathbf{2 0 0 6 - 0 7}$ & 1340350 & 536060 & 2504.14 \\
\hline $\mathbf{2 0 0 7 - 0 8}$ & 1365277 & 547371 & 2524.95 \\
\hline $\mathbf{2 0 0 8 - 0 9}$ & 1465526 & 544050 & 2694.43 \\
\hline $\mathbf{2 0 0 9 - 1 0}$ & 1415290 & 545933 & 2593.36 \\
\hline $\mathbf{2 0 1 0 - 1 1}$ & 1500676 & 547052 & 2744.57 \\
\hline $\mathbf{2 0 1 1 - 1 2}$ & 1612846 & 549816 & 2934.71 \\
\hline $\mathbf{2 0 1 2 - 1 3}$ & 1663273 & 551832 & 3015.42 \\
\hline $\mathbf{2 0 1 3 - 1 4}$ & 1466648 & 553129 & 2652.51 \\
\hline $\mathbf{2 0 1 4 - 1 5}$ & 1026271 & 571909 & 1794.45 \\
\hline Maximum & $\mathbf{1 6 6 3 2 7 3}$ & $\mathbf{5 7 1 9 0 9}$ & $\mathbf{3 0 1 5 . 4 2}$ \\
\hline LGR (\%) & $\mathbf{2 . 4 8}$ & $\mathbf{0 . 8 3}$ & $\mathbf{1 . 7 2}$ \\
\hline CGR (\%) & $\mathbf{2 . 4 8}$ & $\mathbf{0 . 8 4}$ & $\mathbf{1 . 6 3}$ \\
\hline CV (\%) & $\mathbf{1 6 . 9 3}$ & $\mathbf{3 . 8 8}$ & $\mathbf{1 5 . 6 9}$ \\
\hline
\end{tabular}


Table.2 Productivity and CGR of production

\begin{tabular}{|c|c|c|}
\hline & Productivity (Kg/Ha.) & CGR of Production (\%) \\
\hline Varanasi & 2407.76(Max:3015) & 1.63 \\
\hline Eastern UP & 3206.00 & 1.88 \\
\hline UP & 3113.00 & 1.05 \\
\hline Punjab & 4693.00 & 1.00 \\
\hline India & 3075 & 2.56 \\
\hline
\end{tabular}

\section{Growth rates in area}

In Varanasi division the coefficient of variation recorded for the study period was 3.88 per-cent and the linear and compound growth rates recorded during study period were 0.83 and 0.84 per-cent per annum respectively (Table 1).The area of wheat in Varanasi division of Eastern Uttar Pradesh exhibited a positive trend which indicates preference of farmers for wheat cultivation (Fig. 2).

\section{Growth rates in productivity}

Regarding the productivity of wheat in Varanasi division of eastern Uttar Pradesh during the study period (2000-01 to 2014-15) the maximum productivity was $3015 \mathrm{~kg} / \mathrm{ha}$ which is close to level of UP and India. How it is much less than Punjab productivity. Productivity of Varanasi division of Eastern Uttar Pradesh showed a coefficient of variation 15.69 per-cent. Linear and Compound growth rate observed were 1.72 and 1.63 per-cent respectively. The productivity growth rates of wheat in the division exhibit positive but decline in 201415 due to severe drought (Fig. 3).

As a whole, the growth rates of production were higher than area and productivity.

Year to Year fluctuation is alarming and indicates that Irrigation system, though published figure show more than $90 \%$ area is irrigated-is not robust and effective when there is severe drought. Years (2014-2015) had severe drought and production, productivity reached below the level of Year 2001 which strongly indicates vulnerability of production system even where Irrigated Area is more than 90 percent. This implies that requisite irrigation is not possible which needs to be addressed as early as possible.

Table 2 shows that productivity of Varanasi division is less than Eastern UP, UP, India, Punjab. Growth Rate of production of Varanasi division is 1.63 per cent and can further go up by intervention of Technology and improved Irrigation System. The study shows that Varanasi has production and productivity more suffered badly in drought year which calls for strengthening of Irrigation resources along with adoption of modern technology practices.

\section{References}

Manvendra Singh and K. Supriya (2017) Growth Rate and Trend Analysis of Wheat Crop in Uttar Pradesh, India. Int. J. Curr. Microbiol. App. Sci, 6(7): 2295-2301.

Neeraj Singh, Piyush Kumar Singh and Shri Sunil Kumar (2018) Growth Rate of Wheat Crop in Azamgarh Division of Eastern Uttar Pradesh, India. Int.J.Curr.Microbiol.App.Sci. $\quad 7(03)$ : 3348-3352.

Prajneshu and K. P. Chandran (2005) Computation of Compound Growth Rates in Agriculture. Agricultural 
Economics Research Review, Vol. 18: Srivastava S.C., Singh, B.K., Sudeep S Tomar 317-324.

Singh, R. P. (2003) Analysis of Growth Performance of Wheat Crop in Jharkhand; J. Res. Birsa Agri. Univ., 15(2): 217-223. and Yadava, H.S (2013) Growth Pattern of Major Pulses in Eastern Uttar Pradesh. International Journal of Farm Sciences, 3(2): 1-9.

\section{How to cite this article:}

Piyush Kumar Singh, Neeraj Singh, Sunil Kumar and Chaturvedi, V.D. 2018. Growth Rate of Wheat Crop in Varanasi division of Eastern Uttar Pradesh, India. Int.J.Curr.Microbiol.App.Sci. 7(05): 1939-1944. doi: https://doi.org/10.20546/ijcmas.2018.705.227. 